\title{
ОСОБЕННОСТИ ИОННОГО ПЕРЕНОСА В НАНОРАЗМЕРНОЙ РЕШЕТКЕ СУПЕРИОННОГО ПРОВОДНИКА $\mathrm{LaF}_{3}$
}

\author{
В.Ф. Криворотов, С.З. Мирзаев, Г.С. Нуждов \\ Институт ионно-плазменных и лазерных технологий АН РУз, 100125 Ташкент, Узбекистан \\ valeriy.1980@mail.ru \\ (Получена 04.08.2017)
}

\begin{abstract}
Мақ̆олада $X, Y$ ва $Z$ кристаллографик ўқплари бўйлаб, мос равишда $3.5 \times 2.0 \times 2.2$ нм ўлчамли, 1200 та иондан иборат суперионли $\mathrm{LaF}_{3}$ кристалл нанопанжарадаги ички кристалл рельефи профилининг квант-кимёвий хиссоблаш натижалари кўрсатилган. МОРАС 2016 дастурлаш пакети ёрдамида энг тез эрувчи $F_{1}$ ионли панжарада тартибсиланиш элементар актида нанопанжаранинг марказий қисмидаги потенциал рельеф хисоблаш профили олиб борилган. Диэлектрик фазада $\dot{\mathrm{F}}_{1}$ хุаракатига қุаршилик қุилувчи $\mathrm{LaF}_{3}$ кристалларнинг $E_{m}$ тўсиклар эффектив катталиги 0.37 эВ га тенглиги аникјланган, суперион холатда эса бу 0.15 эB гача камайган бўлган. Диэлектрик холатда $\mathrm{F}_{1}$ панжара ионларининг тартибсизланиш активация энергиясининг қиймати 0.16 эВ ва суперионли фаза учун 0.04 эВ га тенглиги аниқ़лаган. Диэлектрик холатдаги кристалларда кристаллографик $X$ ўқи йўналишида уч ўлчовли $\mathrm{LaF}_{3}$ нанопанжараси $X Y$ ва $X Z$ ён сиртида, $\mathrm{F}_{1}$ ионлар кўчган холатдаги потенциал рельеф хєисоблаш профили кўрсатилди. Бу холат учун $\mathrm{LaF}_{3}$ нанопанжара марказ кূисмида активацион тўсикฺларнинг 1.5-2 баробар камайишга эришганлиги олинди.
\end{abstract}

Представлены результаты квантовохимических расчетов по программе МОРАС 2016 профиля внутрикристаллического потенциального рельефа в нанорешетке суперионного кристалла $\mathrm{LaF}_{3}$, содержащей 1200 ионов, размером $3.5 \times 2.0 \times 2.2$ нм соответственно вдоль кристаллографических осей $X, Y$ и $Z$. Расчеты проведены для центральной части нанорешетки при элементарном акте разупорядочения в самой легкоплавкой подрешетке ионов $\mathrm{F}_{1}$. Установлено, что в диэлектрической фазе кристалла $\mathrm{LaF}_{3}$ эффективная величина барьеров $E_{m}$, препятствующих движению $\mathrm{F}_{1}$, равна $0.37 \mathrm{eV}$, в суперионном состоянии барьер уменьшается до $0.15 \mathrm{eV}$. Значение энергии $E_{a}$ активации разупорядочения подрешетки ионов $\mathrm{F}_{1}$ в диэлектрическом состоянии равно $0.16 \mathrm{eV}$ и $0.04 \mathrm{eV}$ для суперионной фазы. Представлены расчеты профиля потенциального рельефа на поверхности граней $X Y$ и $X Z$ нанорешетки $\mathrm{LaF}_{3}$ при перемещении иона $\mathrm{F}_{1}$ в направлении оси $X$ в диэлектрическом состоянии кристалла. Полученные для этого случая активационные барьеры в $1.5-2$ раза меньше барьеров в центральной части нанорешетки $\mathrm{LaF}_{3}$.

The results of quantum-chemical calculations of the intracrystalline potential relief profile in a nanolattices of a superionic $\mathrm{LaF}_{3}$ crystal containing 1200 ions, measuring $3.5 \times 2.0 \times 2.2 \mathrm{~nm}$, respectively along the crystallographic axes $X, Y$, and $Z$ are calculated. Using the software package MORAS 2016, the profile of the potential relief in the central part of nanocell with an elementary disordering event in the most fusible sublattice of the ions $F_{1}$. It is established that in the dielectric phase the effective value of the barrier $E_{m}$ preventing the motion of $\mathrm{F}_{1}$ is $0.37 \mathrm{eV}$, in the superionic state the barrier decreases to $0.15 \mathrm{eV}$. The value of disordering the activation energy $E_{a}$ of the ion sublattice $\mathrm{F}_{1}$ in the dielectric state is $0.16 \mathrm{eV}$ and $0.04 \mathrm{eV}$ for the superionic phase. The potential relief profiles are calculated on the $X Y$ and $X Z$ face surfaces as the ion $\mathrm{F}_{1}$ moves in the direction of the crystallographic $X$ axis in the dielectric state of the crystal. The activation barriers obtained for this case are 1.5-2 two times smaller than the barriers in the central part of the $\mathrm{LaF}_{3}$ nanolattices.

\section{І. ВВЕДЕНИЕ}

Интерес, проявляемый специалистами по исследованию процессов переноса в твердых телах ко фторпроводящим ионным проводникам с общей формулой $\mathrm{LnF}_{3}$ 
( $\mathrm{Ln}-\mathrm{La}, \mathrm{Ce}, \mathrm{Pr})$, в первую очередь, определяется широкими возможностями их приложения в различных технических областях. Наряду с тем, что эти материалы интересны как модельные системы с достаточно простой двухкомпонентной решеткой, обеспечивающей относительно высокие электролитические свойства, они крайне перспективны в качестве материала для рабочих модулей в твердотельных батареях, электрохромных дисплеях, газоаналитических датчиках и различных микроионных устройствах [1-6]. Достаточно важным фактором при различных технических приложениях выступает и то обстоятельство, что относительно высокой ионной проводимостью кристаллы $\mathrm{LnF}_{3}$ обладают уже при комнатной температуре ( $T \approx 300 \mathrm{~K})$. Тогда как, например, оксидные твердые электролиты со структурой флюорита имеют высокие электропроводящие свойства лишь при высоких температурах $(T>900 \mathrm{~K})$. Такая относительно низкотемпературная анионная проводимость кристаллов $\mathrm{LnF}_{3}$ определяется тем, что анионы фтора имеют сравнительно малые размеры (около 0.23 нм), а потенциальные барьеры, ограничивающие их движение, в суперионной (СИ) фазе $(T>260-280 \mathrm{~K}$ [7]) не превосходят 2.0-3.0 kT [8,9].

Как известно, активное разупорядочение анионной подрешетки, например, в кристалле $\mathrm{LaF}_{3}$, определяемое высокой подвижностью ионов фтора, наблюдается в области температур 260-540 К и продолжается до температуры плавления решетки [10-12]. Причем в области 260-320 К разупорядочение решетки определяется движением ионов в подрешетке $F_{1}$, составляющих $2 / 3$ от общего числа ионов фтора. Оставшиеся ионы фтора, $\mathrm{F}_{2}$ и $\mathrm{F}_{3}$, образуют вместе с катионами металла анион-катионные плоскости в структуре решетки. Подрешетки этих ионов разупорядочиваются (“плавятся”) при температурах, превышающих 360-420 К [1214].

В предыдущих работах авторами было показано [9, 15], что высокая анионная подвижность СИ материалов сохраняется даже в ультрадисперсных кристаллитах с числом частиц в решетке 600-1000. Иными словами, в наноструктурированных материалах с характерным размером решеток порядка 3-5 нм полностью сохраняются важнейшие качества объемных СИ материалов, например, высокие электропроводящие свойства. Таким образом, можно считать очевидным, что протекающие в наноразмерных структурах процессы могут лежать в основе перспективных твердотельных нанотехнологий, направленных на решение одной из актуальных задач современной химии и физики твердого тела - разработку и синтез наноструктурированных функциональных материалов с необычными свойствами. С учетом сказанного, в плане технических приложений представляется крайне интересным установить некоторое соответствие между линейными размерами нанорешетки СИ проводника и активационными энергиями, которые определяют эффективность ионного переноса в его решетке. Не менее интересно установить значения активационных энергий в различных областях нанорешетки $\mathrm{LaF}_{3}$, например, на гранях решетки и в ее центре.

Также представляется актуальным и важным рассчитать (на примере нанорешетки СИ кристалла $\mathrm{LaF}_{3}$ ) энергетические параметры переноса ионов в области фазовых превращений (ФП), которые детально описывали бы динамику внутрикристаллического потенциального рельефа в области температур $T<T_{c}=$ $263 \mathrm{~K}$ [16] - диэлектрическая (ДЭ) фаза кристалла $\mathrm{LaF}_{3}$, и $T \geq T_{c}$ (СИ фаза). Для этого используем то обстоятельство, что вследствие высокой ионности связей в 
кристаллах $\mathrm{LnF}_{3} \quad(\approx 0.95-0.96 \quad[17])$ ковалентная составляющая межионных взаимодействий не превышает $5 \%$. И, следовательно, энергия связей в решетке $\mathrm{LnF}_{3}$ с погрешностью не более 5-8\% определяется потенциальной энергией системы частиц, локализованных в минимумах решеточного потенциала [18]. Из этого следует, что для описания и расчета энергии межчастичных взаимодействий в решетке $\mathrm{LaF}_{3}$ (которыми в общем случае и определяется внутрикристаллический потенциальный рельеф) в качестве определяющего фактора с погрешностью не хуже отмеченной выше можно использовать кулоновское приближение для массива сферически-симметричных заряженных частиц $\left[\begin{array}{ll}13, & 19] .\end{array}\right.$ Квантовохимические расчеты других межчастичных взаимодействий в кристаллической решетке в этом случае выступают в качестве важного дополнительного фактора.

\section{II. МЕТОДИКА РАСЧЕТОВ}

Для проведения таких расчетов использовался пакет квантовохимических программ МОРАС 2016 [20]. В основу таких программ положено решение уравнения Шредингера полуэмпирическими методами квантовой химии. При расчетах решеточной энергии связей в кристалле $\mathrm{LaF}_{3}$ использовали параметризацию РМ6 с расширенным набором элементов, включающим элементы лантан и фтор. В контексте сказанного выше, в процессе расчетов энергия связей системы частиц (ионов) определялась большим числом “энергетических” членов, которые обусловлены взаимодействиями различных типов (ядро-ядро, электронная оболочка-ядро и др.) с учетом как дальнодействующих, так и короткодействующих потенциалов. Таким образом, энергия межчастичных связей в рассматриваемой далее нанорешетке $\mathrm{LaF}_{3}$, в физике твердого тела называемая решеточной энергией сцепления (энергией когезии), рассчитывалась в физически достаточно адекватном приближении.

Как уже отмечалось, с ошибкой около 5\% можно допустить, что в решетке $\mathrm{LaF}_{3}$ распределение зарядов в катионах металла и анионах фтора сферически симметричное. Иными словами, в решетке $\mathrm{LaF}_{3}$ практически нет направленных связей, и для описания взаимодействия между частицами с хорошей точностью можно использовать “точечное приближение”. Поэтому при расчетах катионам был приписан знак +3 , а анионам задавался знак -1 . Помимо этого, при расчетах учитывался размер ионов, и поэтому “точечное приближение” было достаточно условным. С учетом сказанного, погрешность при вычислении приведенных в работе значений активационных энергий не превышала 6-8\%.

Расчеты профиля потенциального рельефа сделаны для трехмерной (“кубической”) нанорешетки с линейными размерами. $3.5 \times 2.0 \times 2.2$ нм. Значения 3.5

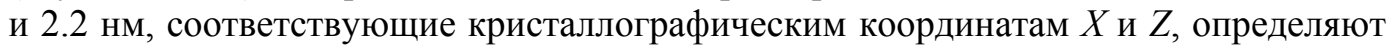
величину ребер куба вдоль постоянных решетки $a$ и $c$, а параметр 2.0 нм, соответствующий координате $Y$, показывает величину ребра куба вдоль прямой, составляющей линейный угол $30^{\circ}$ с постоянной решетки $b$, дополняя угол $60^{\circ}$ между постоянными решетки $a$ и $b$ до $90^{\circ}$.

На начальном этапе рассчитывали потенциальную энергию связей идеальной нанорешетки, в которой ионы занимают равновесные (узельные) позиции в соответствии с еe низкотемпературной структурой, а междоузлия, с ростом температуры участвующие в процессе разупорядочения решетки $[13,21]$, остаются 
свободными от подвижных ионов фтора. Для получения энергетического профиля потенциального рельефа в ДЭ фазе один из ионов $\mathrm{F}_{1}$ (рис. 1) последовательными 8 шагами перемещался в междоузлие в центральной части идеальной решетки. Энергия связей решетки рассчитывалась для каждого такого шага. Затем из пошаговых значений энергии связей решетки вычиталось установленное ранее значение когезийной энергии идеальной решетки. Полученные значения избыточной энергии задавали профиль потенциального рельефа, вдоль которого ион $\mathrm{F}_{1}$ перемещается из узла в междоузлие в ДЭ состоянии кристалла $\mathrm{LaF}_{3}$.

Для расчета внутрикристаллического профиля в нанорешетке $\mathrm{LaF}_{3}$ в CИ фазе все междоузлия нанорешетки (кроме одного, расположенного в ее центральной части) заполнялись ионами фтора и рассчитывалась энергия связей. Затем в свободное междоузлие по описанной выше методике перемещался один из ионов $F_{1}$ и производился расчет когезийной энергии в нанорешетке $\mathrm{LaF}_{3}$ при каждом шаге. Таким способом с учетом энергии связей в “недозаполненной” решетке по 8 точкам получен профиль потенциального рельефа, по которому ион $\mathrm{F}_{1}$ совершает элементарный акт разупорядочения в $\mathrm{CИ}$ состоянии $\mathrm{LaF}_{3}$. С учетом того, что перемещение иона совершалось в потенциальном поле, образованном всеми остальными частицами решетки, такой перенос иона позволял достаточно корректно вычислить профиль рельефа между конкретным анионным узлом и центром междоузлия $[15,22]$.

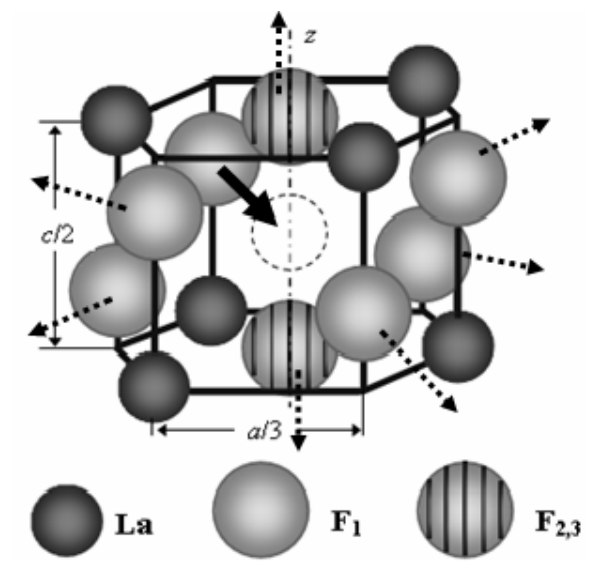

Рис. 1. Конфигурация ионов фтора в решетке $\mathrm{LaF}_{3}$ с межузельной полостью (показана пунктирной окружностью). Пунктирными стрелками показаны возможные смещения ионов $\mathrm{F}_{1}$ и $\mathrm{F}_{2,3}$.

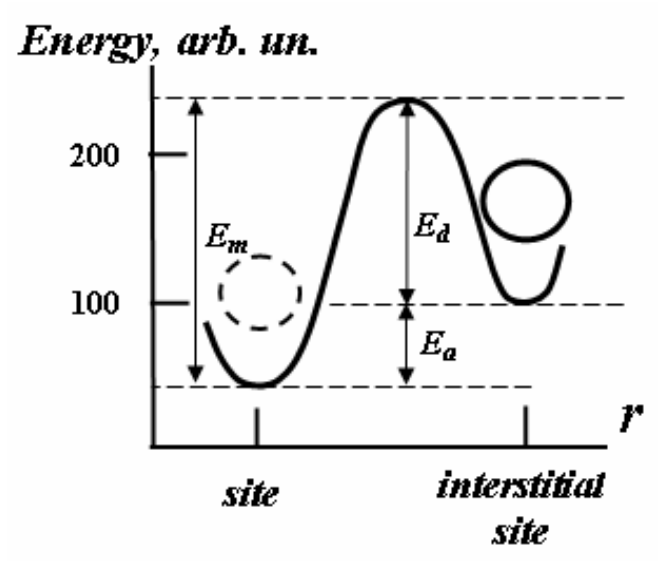

Рис. 2. Схема профиля потенциального рельефа между вакансией $\mathrm{F}_{1}$ и центром междоузлия в решетке типа тисонита, показывающая связь между величиной потенциального барьера $E_{m}$, энергией активации движения $E_{d}$ и энергией $E_{a}$ активации разупорядочения подрешетки ионов $\mathrm{F}_{1}$.

Из формы профиля потенциального рельефа (рис. 2) можно непосредственно получить различные активационные энергии для движения ионов в центральной части нанорешетки: величину барьера $E_{m}$, который преодолевает ион $\mathrm{F}_{1}$ при перемещении в междоузлие, энергию $E_{a}$ разупорядочения подрешетки $\mathrm{F}_{1}$ (энергию образования пары точечных дефектов типа вакансия $\mathrm{F}_{1}$-межузельный анион), a 
также энергию $E_{d}$ движения иона фтора, связанную с величиной барьера известным соотношением $E_{m}=E_{a}+E_{d}$ [23-25].

Отдельный интерес представляет расчет активационных энергий $E_{m}, E_{a}$ и $E_{d}$, полученных при перемещении иона $\mathrm{F}_{1}$ вдоль различных граней нанорешетки $\mathrm{LaF}_{3}$, в частности, параллельных и перпендикулярных анионно-катионным плоскостям. Таким образом, изменяя начальные положения иона $\mathrm{F}_{1}$ на тех или иных гранях нанорешетки, можно прописать профиль внутрикристаллического потенциального рельефа на пути перемещения ионов $\mathrm{F}_{1}$ в соответствующие междоузлия в различных частях нанорешетки $\mathrm{LaF}_{3}$.

\section{ІІІ. РЕЗУЛЬТАТЫ И ОБСУЖДЕНИЕ}

Как уже отмечалось, в плане технического использования наноразмерных материалов крайне интересно установить определенное соответствие между степенью разупорядочения исследуемой нанорешетки и активационными энергиями $E_{m}, E_{d}$ и $E_{a}$, которые определяют основные параметры ионного переноса в $\mathrm{LaF}_{3}$.

\section{Energy, eV}

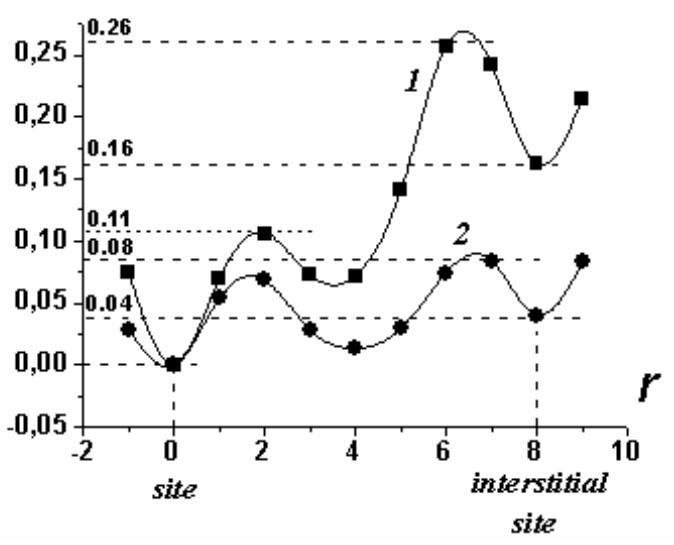

Рис. 3. Профили потенциального рельефа в “кубической" нанорешетке $\mathrm{LaF}_{3}$ при перемещении иона $\mathrm{F}_{1}$ из узла в междоузлие в центральной ее части: кривая 1 - ДЭ фаза $\left(T<T_{c}\right)$, кривая $2-$ СИ фаза $\left(T \geq T_{c}\right)$.
Завершая описание барьеров на пути перемещения иона $\mathrm{F}_{1}$, следует заметить, что однозначно не установлено точного критерия определения эффективной величины нескольких близко расположенных барьеров на пути перемещения мобильной частицы [24]. Достаточно разумным представляется положение, по которому за эффективное значение таких барьеров в первом приближении можно принять их суммарную величину. Тогда эффективная величина всех барьеров $E_{m}$ на пути перемещения иона $\mathrm{F}_{1}$, полученных квантовохимическими расчетами, для кубической решетки примерно равна их сумме, и в ДЭ фазе (кривая 1 рис. 3) составляет $E_{m} \approx 0.37 \mathrm{eV}(0.11 \mathrm{eV}+0.26 \mathrm{eV})$. В СИ фазе (кривая 2) эффективная величина барьеров $E_{m}$ уменьшается более чем в два раза, до значения $0.15 \mathrm{eV}(0.07 \mathrm{eV}+0.08 \mathrm{eV})$. Тогда значения энергии $E_{d}$ движения в соответствии с соотношением $E_{m}=E_{a}+E_{d}$ составляют $0.21 \mathrm{eV}(0.37 \mathrm{eV}-0.16 \mathrm{eV})$ в ДЭ фазе и 0.11 $\mathrm{eV}(0.15 \mathrm{eV}-0.04 \mathrm{eV})$ для СИ состояния. Здесь значения 0.16 и $0.04 \mathrm{eV}$ соответствуют активационным энергиям $E_{a}$ разупорядочения подрешетки $\mathrm{F}_{1}$ соответственно в ДЭ и СИ фазах $\mathrm{LaF}_{3}$ (рис. 3). Для сравнения отметим, что по данным квазиупругого рассеяния света в $\mathrm{LaF}_{3}$ величина барьеров $E_{m}$ составляет $0.48 \mathrm{eV}$ в ДЭ состоянии и $0.09 \mathrm{eV}$ в СИ фазе $[8,22]$. Видно, что эти значения неплохо соотносятся со значениями барьеров $E_{m}$, полученными квантовохимическими расчетами. 
Заметим, что между значениями энергий $E_{a}$ активации разупорядочения решеток $\mathrm{LaF}_{3}$, полученными различными способами, соответствие также хорошее. Так, значения $E_{a}=0.20 \mathrm{eV}$ (ДЭ фаза) и $E_{a}=0.04 \mathrm{eV}$ (СИ фаза), полученные по данным Раман-спектров [25], хорошо согласуются соответственно со значениями $E_{a}=0.16 \mathrm{eV}$ (ДЭ фаза) и $E_{a}=0.04 \mathrm{eV}$ (СИ фаза), полученными квантовохимическими расчетами (рис. 3). Таким образом, для исследуемой нанорешетки $\mathrm{LaF}_{3}$ активационные энергии $E_{a}, E_{d}$ и $E_{m}$ в ДЭ фазе составляют соответственно 0.16 , 0.21 и $0.37 \mathrm{eV}$, которые в СИ состоянии уменьшаются в несколько раз, до значений $0.04,0.11$ и $0.15 \mathrm{eV}$. Такое заметное уменьшение активационных энергий определяется так называемыми кооперативными взаимодействиями в “квазижидкой” подрешетке и обуславливает возникновение СИ состояния в нанорешетке $\mathrm{LaF}_{3}$ [23]. Следует также отметить, что если в данное междоузлие перемещать соседние ионы $\mathrm{F}_{1}$ (расположенные по гофрированному кольцу под углом $60^{\circ}$ друг относительно друга в плоскости $X Y$ (рис. 1), то вид потенциальных кривых 1 и 2 для центральной части кубической нанорешетки изменяется лишь на 2-6\%.

Представляется интересным получить потенциальные профили не только при перемещении ионов $\mathrm{F}_{1}$ в центральной части нанорешетки, но и на поверхности ее граней. Причем в одном случае перемещение иона $\mathrm{F}_{1}$ в междоузлие будет происходить параллельно постоянной решетки $a$ (параллельно кристаллографической оси $X$ ) в плоскости грани $X Y$, параллельной анион-катионным плоскостям, а в другом случае - также параллельно постоянной решетки $a$, но в плоскости грани $X Z$, перпендикулярной анион-катионным плоскостям (рис. 4). На рис. 4 стрелки показывают направление прыжка ионов $\mathrm{F}_{1}$ из узельных позиций решетки в межузельные в центральной части нанорешетки и на различных ее гранях. Цифры 1,2 и 3 соответствуют кривым 1, 2 и 3 на рис. 5.

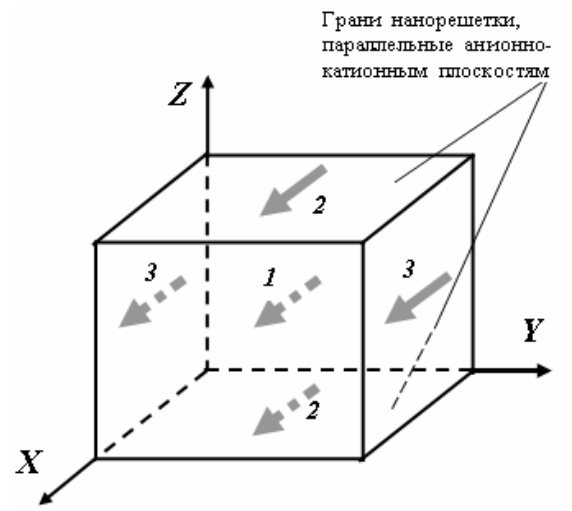

Рис. 4. Изометрическая картина движения иона $\mathrm{F}_{1}$ в центре (стрелка 1) и в плоскости смежных граней $X Y$ (стрелки 2) и $X Z$ (стрелки 3) нанорешетки в лабораторной системе координат.

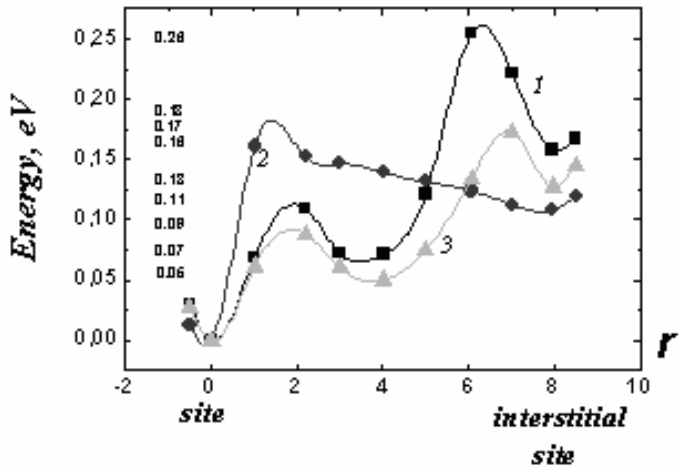

Рис. 5. Профили потенциальных рельефов в ДЭ фазе кристалла $\mathrm{LaF}_{3}$, связанных с перемещением ионов $\mathrm{F}_{1}$ в кубической нанорешетке: 1 - перемещение иона $\mathrm{F}_{1}$ в междоузлие в центральной части нанорешетки, 2 и 3 перемещение ионов $\mathrm{F}_{1}$ в междоузлия в смежных гранях нанорешетки, параллельных и перпендикулярных анион-катионным плоскостям. 
На рис. 5 показаны результаты расчетов профилей потенциальных рельефов в ДЭ фазе кристалла $\mathrm{LaF}_{3}$, связанных с перемещением отдельных ионов $\mathrm{F}_{1}$ в различных частях кубической нанорешетки $3.5 \times 2.0 \times 2.2$ нм. Кривая 1 , приведенная для сравнения, описывает профиль потенциального рельефа в ДЭ фазе $\mathrm{LaF}_{3}$ при перемещении иона $\mathrm{F}_{1}$ в междоузлие в центральной части нанорешетки; кривые же 2 и 3 показывают профили потенциальных рельефов в ДЭ состоянии, связанные с перемещением в междоузлия отдельных поверхностных ионов $\mathrm{F}_{1}$, расположенных на двух смежных гранях кубической нанорешетки. Поскольку противоположные грани такой решетки структурно эквивалентны, значит, потенциальные профили на них описываются одинаковыми кривыми.

Анализ кривой 2 , которая описывает профиль рельефа при движении иона $\mathrm{F}_{1}$ в плоскости грани $X Y$ в направлении кристаллографической координаты $X$, параллельной анион-катионным плоскостям, показывает, что в самом начале движения ион фтора наталкивается на потенциальный барьер $E_{m}=0.18 \mathrm{eV}$, образуемый ближайшими ионами фтора. Преодолев барьер, ион скатывается в междоузлие по пологой кривой без заметных особенностей. Почти линейный ход кривой 2 после второго шага обусловлен тем, что по мере продвижения подвижного иона к центру междоузлия, ионы фтора, формирующие его, несколько раздвигаются (рис. 1), как бы уступая ему дорогу и определяя тем самым достаточно высокую однородность потенциальной поверхности на грани $X Y$ без локальных минимумов и пиков. В конечном положении (в междоузлии) энергетическое состояние иона $\mathrm{F}_{1}$ определяется значением $E_{a}=0.11 \mathrm{eV}$ - энергией разупорядочения подрешетки $\mathrm{F}_{1}$ в ДЭ фазе $\mathrm{LaF}_{3}$.

Отметим, что при перемещении иона фтора по грани $X Y$ потенциальный барьер $E_{m}=0.18 \mathrm{eV}$, ограничивающий его движение вдоль постоянной решетки $a$, в два раза меньше барьера $E_{m}=0.37 \mathrm{eV}$, препятствующего такому же перемещению иона $\mathrm{F}_{1}$ в центральных областях нанорешетки. Иными словами, прыжки $\mathrm{F}_{1}$ вдоль грани $X Y$ в соответствии с соотношением $v_{i} \sim v_{0} \exp \left(-E_{m} / k T\right)$ для области температур $T<T_{c}$ реализуются более чем на три порядка чаще (при прочих равных условиях), чем в центральных областях нанорешетки (здесь $v_{0}$ - узельная частота колебаний иона $\mathrm{F}_{1}$, $v_{i}$ - частота его попадания на вершину барьера $E_{m}$ ).

Совершенно иной вид имеет потенциальный профиль при перемещении иона $\mathrm{F}_{1}$ по грани $X Z$, перпендикулярной анион-катионным плоскостям (кривая 3 ). В этом случае эффективный барьер $E_{m}=0.26 \mathrm{eV}(0.09 \mathrm{eV}+0.17 \mathrm{eV})$, а энергия $E_{a}$ разупорядочения подрешетки $\mathrm{F}_{1}$ на грани $X Z$ равна $0.13 \mathrm{eV}$ (рис. 5). Такой барьер $E_{m}$ лишь на $30 \%$ меньше барьера $E_{m}=0.37 \mathrm{eV}$, ограничивающего движение иона $\mathrm{F}_{1}$ в центральных областях решетки. Это обстоятельство позволяет прыжкам $\mathrm{F}_{1}$ по грани $X Z$ в области температур $T<T_{c}$ осуществляться примерно на два порядка чаще, чем в центральных областях нанорешетки. Иными словами, в ДЭ фазе перемещение отдельных поверхностных ионов $\mathrm{F}_{1}$ в плоскости грани $X Z$ кубической нанорешетки $\mathrm{LaF}_{3}$ в несколько десятков раз эффективней, чем, например, в центральных областях нанорешетки.

Полученные результаты показывают, что наиболее активный (массовый) перенос ионов $\mathrm{F}_{1}$ в направлении кристаллографической оси $X$ для области температур $T<T_{c}$ наблюдается на боковых (относительно направления движения ионов $\mathrm{F}_{1}$ ) гранях нанорешетки $\mathrm{LaF}_{3}$. Из чего следует, что самые разупорядоченные (“квазижидкие”) области нанорешетки в ДЭ состоянии $\mathrm{LaF}_{3}$ - это грани $X Y$ и $X Z$, а 
также противоположные им грани нанорешетки. То есть, для нанорешетки $\mathrm{LaF}_{3}$ в области температур $T<T_{c}$, когда разупорядочиваются отдельные ионы подрешетки $\mathrm{F}_{1}[7,13,26]$, по-видимому, имеет место некоторый аналог скин-эффекта (если высокую локальную подвижность ионов фтора понимать как необходимое условие направленного переноса ионов фтора).

$\mathrm{B}$ нанорешетке кристалла $\mathrm{LaF}_{3}$ этот эффект характеризуется тем, что процесс разупорядочения самой легкоплавкой подрешетки $\mathrm{F}_{1}$ наиболее активно идет на гранях нанорешетки, параллельных направлению переноса ионов фтора вдоль кристаллографической оси $X$ (рис. 4). Между тем, этот вывод можно назвать достаточно ожидаемым, поскольку число связей для поверхностных ионов, как правило, заметно меньше числа связей для ионов, расположенных во внутренних областях нанорешетки. По этой причине можно ожидать, что и при более высоких температурах ( $T>T_{c}$, СИ фаза) перенос поверхностных ионов $\mathrm{F}_{1}$ будет намного эффективнее переноса ионов в других областях нанорешетки. Отсюда следует интересное заключение о том, что ВП состояние, в первую очередь, наступает в поверхностных областях нанорешетки $\mathrm{LaF}_{3}$, с ростом температуры распространяясь на весь ее объем.

Проведенные расчеты энергетических параметров движения ионов $\mathrm{F}_{1}$ показали, что в рассматриваемом случае ионы фтора наиболее активно разупорядочиваются не в центральных областях нанорешетки, а в ее поверхностных слоях, в плоскости граней $X Y$ и $X Z$, параллельных направлению перемещения ионов $\mathrm{F}_{1}$. Понятно, что этот эффект наблюдается лишь при условии, что число “эквивалентных" междоузлий в приповерхностных областях нанорешетки примерно равно числу междоузлий в ее центральной части, что для трехмерных наноструктурированных решеток выполняется практически всегда. Таким образом, для ряда СИ трифторидов (на примере кристалла $\mathrm{LaF}_{3}$ ) проведены квантовохимические расчеты решеточной энергии и определены внутрикристаллические потенциальные барьеры, которые преодолевают подвижные ионы $F_{1}$ при перемещении в “эквивалентное” междоузлие в широком интервале температур.

Нами исследовались особенности перемещения только ионов $\mathrm{F}_{1}$, поскольку именно они составляют основной массив подвижных ионов фтора, определяющих процесс “плавления" анионной подрешетки $\mathrm{LaF}_{3}$. Следует также заметить, что в связи с невозможностью прямого теоретического расчета электропроводности ионных кристаллов (по причине трудности расчета энергетических параметров, ответственных за ионный перенос) полученные значения $E_{a}, E_{d}$ и $E_{m}$ представляются важными для адекватного описания и понимания основных закономерностей процессов переноса заряда в ионных кристаллах.

\section{IV. ЗАКЛЮЧЕНИЕ}

Важным итогом анализа результатов квантовохимических расчетов потенциального рельефа, преодолеваемого подвижными ионами фтора как в области температур $T<T_{c}$, так и для $T \geq T_{c}$, является заключение о том, что они показывают безусловное наличие в области $T \geq T_{c}$ некоторого эффекта, определяемого высокой концентрацией разупорядоченных ионов. Этот эффект, как уже отмечалось, проявляется в значительном уменьшении параметров потенциального рельефа вблизи дефектов типа вакансия-межузельный ион (рис. 3), и в литературе по СИ проводникам называется кооперативным. Этот вывод получен не путем построения 
соответствующих моделей и связанных с ними предположений и предпосылок, а на базе лишь двух положений. Во-первых, была построена кристаллическая решетка типа тисонита, в которой (для моделирования СИ состояния) каждый шестой ион фтора определенным образом перемещался в ближайшее междоузлие - тем самым задавалась “расплавленная" структура, соответствующая тому или иному типу разупорядочения решетки в ВП фазе. Во-вторых, для СИ кристалла $\mathrm{LaF}_{3}$ были определены значения энергий связей для восьми точек на пути перемещения различных ионов $F_{1}$ из узлов в соответствующие междоузлия. Эти два положения позволили достаточно надежно установить, что при переходе из ДЭ состояния в СИ фазу энергетический рельеф на пути движения иона фтора претерпевает значительные изменения.

Достаточно интересным итогом анализа потенциального рельефа, преодолеваемого подвижными ионами фтора в области температур $T<T_{c}$, представляются следующие заключения, вытекающие из квантовохимических расчетов параметров внутриячеечного потенциального рельефа: 1) для наноразмерных кластеров в полной мере сохраняются основные особенности СИ материалов, и для них можно применять понятия ДЭ и ВП состояний со всеми свойственными им закономерностями; 2) для нанорешеток размером $\approx 3 \times 3 \times 3$ нм установлено, что в плоскости граней $X Y$ и $X Z$ (рис. 4) эффективность переноса ионов $\mathrm{F}_{1}$ в направлении постоянной решетки $a$ в сотни раз превосходит эффективность ионного переноса в других частях нанорешетки кристалла $\mathrm{LaF}_{3}$. Оба эти вывода, очевидно, применимы ко всем СИ трифторидам структурного типа $\mathrm{LaF}_{3}$, поскольку основное различие в их строении - это некоторое (около 1-2\%) уменьшение постоянных решетки $a, b$ и $c$ вдоль лантаноидного ряда.

Приведенные выше выводы могут оказаться важными при выборе формы рабочих элементов на основе наноструктурированных ионопроводящих материалов в различных технических устройствах. В частности, при проектировании энергоемких аккумуляторов и батарей, работающих в области комнатных температур, вместо цилиндрических и прямоугольных проводящих элементов, по-видимому, можно (в целях экономии ионопроводящего материала и уменьшения веса устройства) использовать трубчатые конструкции, ориентированные вдоль постоянной решетки $a$ (или $b$ ), без заметной потери плотности ионного потока.

Таким образом, результаты, получаемые посредством квантовохимических расчетов когезийной энергии нанорешеток СИ материалов, заметно расширяют спектр физических процессов, исследуемых методом компьютерного моделирования. А сами результаты исследований могут быть использованы для оптимизации формы рабочих модулей в процессе создания, например, современных вторичных источников электрической энергии на основе наноструктурированных СИ материалов.

Работа выполнена при финансовой поддержке Государственной программы фундаментальных исследований АН Республики Узбекистан (грант ФА-Ф2-Ф081) и Узбекско-Российского гранта МР-30-2008.

\section{ЛИТЕРАТУРА}

1. Ю.Я. Гуревич, Ю.И. Харкац. Суперионные проводники (Москва, Наука, 1992).

2. T. Tarahashi, K. Kuwabara. Physics and Chemistry of Solid Electrolytes. Ed. I. Yokota (Niigata (Japan), Niigata University, 1990). 
3. В.С. Багоцкий, А.М. Скундин. Химические источники тока (Москва, Энергия, 1981).

4. А.А. Потанин, Российский хим. журн. XLV, № 5-6, 58 (2001).

5. W. Moritz, V.I. Filippov, A.A. Vasiliev, et al. In: 12-th Europ. Symp. Fluorine Chemistry (Germany, Berlin, Aug. 29- Sept. 2, 1998).

6. А.А. Нефедов, С. Сбитнев, С. Фанченко, Письма в ЖЭТФ 24, № 14, 31 (1998).

7. A.F. Privalov, H.-M. Vieth, and I.V. Murin, J. Phys. Chem. Solids 50, № 4, 395 (1989).

8. В.Ф. Криворотов, А.А. Фридман, Е.В. Чарная, Узбек. физич. журн. 13, № 2, 104 (2011).

9. В.Ф. Криворотов, Г.С. Нуждов, А.А. Фридман и др., Электрохимия 49, № 12, 1285 (2013).

10. C. Tien, E.V. Charnaya, A.B. Sherman, ФTT 46, № 9, 1578 (2004).

11. Mohamed El Omari, Jean Sénegas, Jean-Maurice Réau, Solid State Ionics 107, 293 (1998).

12. A.F. Privalov, O. Lips, and F. Fujara, J. Phys.: Condens. Matter 14, 4515 (2002).

13. A. Rhandour, J.M. Reau, S.F. Matar, et al., Mat. Res. Bull. 20, 1309 (1985).

14. V. Trnovcova, L.S. Garashina, A. Skubla, et al., Solid State Ionics 157, 195 (2003).

15. В.Ф. Криворотов, Г.С. Нуждов, Журн. технической физики 82, № 12, 58 (2012).

16. П.К. Хабибуллаев, Л.Н. Ферштат, А.Э. Алиев, Докл. АН СССР 281, № 2, 320 (1985).

17. W. Moritz, V.I. Filippov, A.A. Vasiliev, et al. In: 12th Europ. Symp. Fluorine Chemistry (Germany, Berlin, Aug. 29- Sept. 2, 1998).

18. В.С. Урусов. Теоретическая кристаллохимия (Москва, Изд. МГУ, 1987).

19. Physics of Superionic Conductors. Ed. M.B. Salamon (Springer-Verlag, Berlin-HeidelbergNew York, 1979).

20. MOPAC 2012, James J.P. Stewart (Stewart Computational Chemistry, Colorado Springs, CO, USA), http://openmopac.net.

21. В.Ф. Криворотов, П.К. Хабибуллаев, А.А. Фридман и др., Неорган. материалы 46, № 10,1263 (2010).

22. Валерий Криворотов. Внутреннее движение и кооперативные явления в суперионных трифторидах (Эксперименты, модели, расчеты) (LAMBERT Academic Publishing, Saarbrücken, Deutschland 2013).

23. В.Ф. Криворотов, Журн. технич. физики 83, № 5, 82 (2013).

24. John Manning. Diffusion Kinetics for Atoms in Crystals (Van Nostrand, Princeton, New Jersey, 1968).

25. В.Ф. Криворотов, П.К. Хабибуллаев, А.А. Фридман и др., Неорган. материалы 46, № 7 , 875 (2010).

26. В.Ф. Криворотов, П.К. Хабибуллаев, А.А. Фридман и др., Неорган. материалы 46, № 11, 1387 (2010). 